\title{
Synaptic Competition during the Reformation of a Neuromuscular Map
}

\author{
Michael B. Laskowski, ${ }^{1}$ Howard Colman, ${ }^{2}$ Carla Nelson, ${ }^{2}$ and Jeff W. Lichtman ${ }^{2}$ \\ ${ }^{1}$ WWAMI Medical Program, University of Idaho, Moscow, Idaho 83844-4207, and 2Department of Anatomy and \\ Neurobiology, Washington University, School of Medicine, St. Louis, Missouri 63110
}

\begin{abstract}
We have been studying the mechanisms whereby pools of motor neurons establish a rostrocaudal bias in the position of their synapses in some skeletal muscles. The serratus anterior (SA) muscle of the rat displays a rostrocaudal topographic map before birth, and the topography is re-established after denervation. In this report, we explore the potential role of synaptic competition between innervating axons as a means of generating topographic specificity. We followed the progress of the reformation of this map in neonatal animals under conditions that enhanced the likelihood of observing synaptic competition. This was accomplished by forcing caudal axons to regenerate ahead of rostral axons onto a surgically reduced SA muscle. In this way, caudal $\left(\mathrm{C}_{7}\right)$ motor neurons had unopposed access to vacated synaptic sites on the remaining rostral half of the SA before the return of the rostral $\left(\mathrm{C}_{6}\right)$ axons. Intracellular recording revealed that $2 \mathrm{~d}$ after the second denervation, most of the
\end{abstract}

reinnervated end plates contained only axons from the $\mathrm{C}_{7}$ branch; the remaining reinnervated end plates received input from $\mathrm{C}_{6}$ only or were multiply innervated by $\mathrm{C}_{6}$ and $\mathrm{C}_{7}$ axons. After $6 \mathrm{~d}$, the pattern was reversed, with most end plates innervated exclusively by $C_{6}$. After $17 \mathrm{~d}$, axons from $\mathrm{C}_{6}$ were the sole input to reinnervated end plates. During the transition from $\mathrm{C}_{7}$ - to $\mathrm{C}_{6}$-dominated input, at end plates coinnervated by $\mathrm{C}_{6}$ and $\mathrm{C}_{7}$ axons, the average quantal content from $\mathrm{C}_{6}$ was the same as that from $\mathrm{C}_{7}$; after $7 \mathrm{~d}$, the quantal content of $\mathrm{C}_{6}$ was greater than that of $\mathrm{C}_{7}$. We have thus developed an experimental situation in which the outcome of synaptic competition is predictable and can be influenced by the positional labels associated with axons from different levels in the spinal cord.

Key words: synaptic competition; topography; neuromuscular junction denervation; motor neurons; synapse elimination; end plates
Several lines of recent evidence suggest that the reinnervation of mammalian muscle is more selective than originally thought. It is now well established that pools of spinal motor neurons project onto muscles, forming topographic maps (Swett et al., 1970; Brown and Booth, 1983a,b; Bennett and Lavidis, 1984a,b; Donselaar et al., 1985; Weeks and English, 1985, 1987; Mutai et al., 1986; Laskowski and Sanes, 1987; Bennett and Ho, 1988; Gordon and Richmond, 1990; Welt and Abbs, 1990). The map is detectable in the embryonic rat diaphragm and serratus anterior (SA) muscle at least by embryonic day 17 (Laskowski and High, 1989; Laskowski and Owens, 1994). An important question is whether this topographic map can be re-established after denervation. Previous work from our laboratory and those of others has shown that the spinal motor neuron pools of some muscles re-establish a topographic map after their innervation has been interrupted (Brown and Hardman, 1987; Hardman and Brown, 1987; Laskowski and Sanes, 1988; DeSantis et al., 1992; Grow et al., 1995; see also Wigston and Sanes, 1982, 1985). What we do not know are the mechanisms that guide regenerating axons to their appropriate muscle targets or the processes by which axons are prevented from innervating positionally inappropriate targets.

Topography is re-established early in the process of reinnervation, rather than emerging by selective pruning after an initial period of random innervation (DeSantis et al., 1992). A simple

\footnotetext{
Received April 16, 1998; revised June 11, 1998; accepted July 1, 1998.

This work was supported by grants from the National Institutes of Health to M.B.L. and from the National Institutes of Health and the MDA to J.W.L.

Correspondence should be addressed to Dr. Michael B. Laskowski, WWAMI Medical Program, University of Idaho, Moscow, ID 83844-4207.

Copyright (C) 1998 Society for Neuroscience $\quad 0270-6474 / 98 / 187328-08 \$ 05.00 / 0$
}

explanation is that regenerating neurites proceed down vacated endoneurial sheaths and are thus physically guided to their original end plates (Brown and Hopkins, 1981; Ide et al., 1983; Ide and Kato, 1990). However, even when the respective nerves to the diaphragm and SA muscles were severed and intentionally misaligned, axons re-established a topographic map (Laskowski and Sanes, 1988). Moreover, when the nerve was frozen, causing breaks in the endoneurial sheath, selectivity was also reestablished (DeSantis et al., 1992). Thus although passive guidance undoubtedly plays some role in reinnervation specificity, another more active mechanism must be involved.

One of the advantages offered by the SA muscle is that regenerating caudal axons must necessarily pass over rostral portions of the SA muscle before reaching their eventual caudal targets. Why these caudally directed neurites bypass rostral end plates is not understood, but some explanations can be proposed. First, there is a $4: 1$ ratio of rostral $\left(\mathrm{C}_{6}\right)$ to caudal $\left(\mathrm{C}_{7}\right)$ root axons that innervate the SA muscle (Grow et al., 1995). Second, caudal axons may be physically constrained from innervating vacant rostral end plates or, once at an end plate site, may be incapable of forming functional synapses. Third, regenerating caudal and rostral neurites may innervate vacated end plates and form functional synapses, but eventually any topographically "inappropriate" terminals are suppressed or displaced, yielding a restored map.

To decide among these possibilities, we exploited the model developed previously in our laboratory (Grow et al., 1995). By crushing the LTN to the SA muscle in neonatal rat pups, axons from both $\mathrm{C}_{6}$ and $\mathrm{C}_{7}$ ventral roots began regenerating. Two days later the branch from $\mathrm{C}_{6}$ was crushed, and the caudal half of the 


\section{Serratus Anterior Muscle}

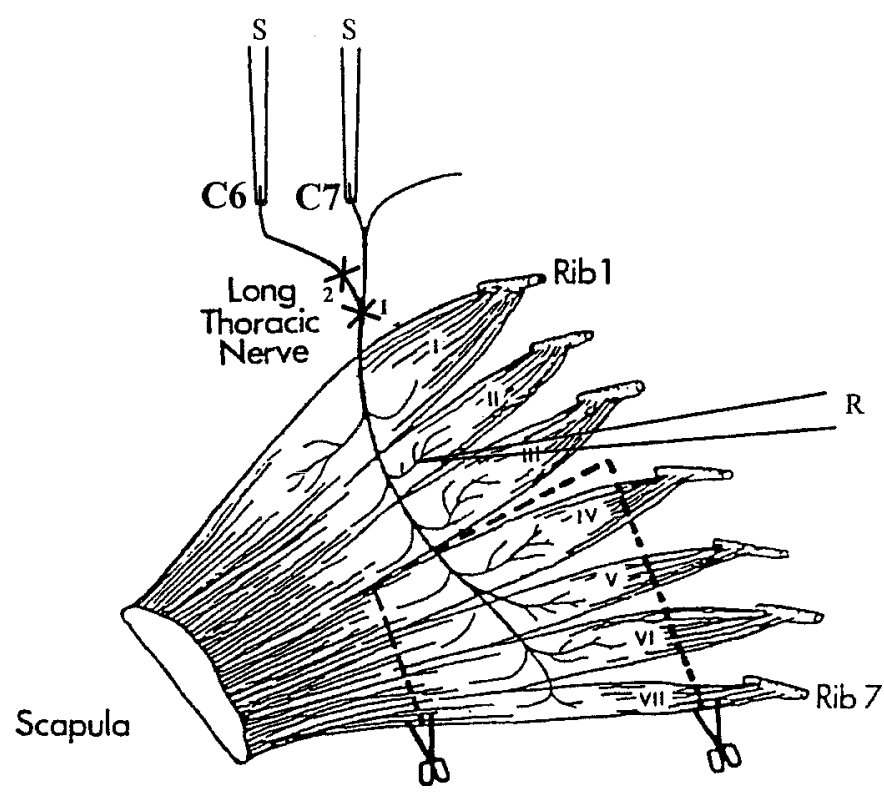

Figure 1. Diagram of the serratus anterior muscle illustrating the surgical procedures used to induce competition between motor neurons originating from different spinal levels for muscle fibers in the same muscle sector. Within $3 \mathrm{~d}$ of birth, the long thoracic nerve was crushed $(X 1)$. Two days later, the $\mathrm{C}_{6}$ branch to the long thoracic nerve was crushed $(X 2)$, and caudal muscle sectors IV-VII were removed (dotted lines). On each day after denervation, muscles were dissected, the $\mathrm{C}_{6}$ and $\mathrm{C}_{7}$ branches were stimulated with suction electrodes, and a microelectrode was inserted into the end plate region of surface muscle fibers in the remaining sectors to assess the source and strength of the innervation.

muscle was removed. This method created a situation in which $\mathrm{C}_{7}$ (caudal) axons were allowed temporary unopposed access to the vacated rostral end plates, while their normal caudal target was absent. If these caudal axons lacked a specific end plate recognition signal or were physically constrained by endoneurial sheaths, they would bypass rostral sectors and continue growing toward caudal sectors. Alternatively, if caudal terminals did form synaptic connections on rostral sectors, they would soon receive competition from the newly regenerating $\mathrm{C}_{6}$ (rostral) axons. We could then monitor electrophysiologically the transition from innervation by $\mathrm{C}_{7}$ to innervation by $\mathrm{C}_{6}$.

\section{MATERIALS AND METHODS}

Denervation procedures. Denervations were performed on Sprague Dawley rats within $3 \mathrm{~d}$ of birth by a method similar to that of Reis and Laskowski (1993). Pups were anesthetized on ice until all spontaneous and reflex movement ceased. Under aseptic conditions, an incision was made in the right axillary region, and the SA muscle with its LTN was located. Using Biologie grade number five jeweler's forceps (Fine Science Tools), we crushed the LTN just proximal to its passage over sector I, the most rostral muscle sector (Fig. 1). The wound was sutured; the pup was rewarmed and, when awake, returned to its mother. Two days later, the pup was reanesthetized on ice, and the incision was reopened. The branch from the $\mathrm{C}_{6}$ spinal nerve that projects to the LTN was located and crushed, and the caudal half of the muscle (containing sectors IV-VII) was removed. The wound was resutured, and after recovery, the pup was returned to its mother. The day of this second nerve crush is referred to in the text as "day $\mathrm{O}$ after denervation." The procedure in which $\mathrm{C}_{6}$ is selectively crushed allows for regeneration of $\mathrm{C}_{7}$ axons $1-2 \mathrm{~d}$ ahead of $\mathrm{C}_{6}$ axons. Over the next $2 \mathrm{~d}$ to 2 weeks, pups were killed, and the right SA muscle along with branches from the $\mathrm{C}_{6}$ and $\mathrm{C}_{7}$ ventral roots were dissected and pinned in a Sylgard-coated Petri dish. Using a silver- cholinesterase stain, [Bodian (1936); as modified in Laskowski et al. (1991)], we confirmed that this reinnervation paradigm did not disrupt the location of neuromuscular junctions on the muscles.

In a second series of experiments, the LTN was crushed, and $2 \mathrm{~d}$ later, the $\mathrm{C}_{6}$ branch was crushed, and the rostral sectors of the muscle (I-III) were removed. A narrow "bridge" of muscle under the LTN, and just slightly wider than the nerve, was left intact so the regenerating nerve could grow back to caudal sectors (IV-VII).

Recording techniques. Muscles were superfused at room temperature with oxygenated mammalian Ringer's solution consisting of (in mM): 144 $\mathrm{NaCl}, 4 \mathrm{KCl}, 1 \mathrm{KH}_{2} \mathrm{PO}_{4}, 1 \mathrm{MgCl}_{2}, 4 \mathrm{HEPES}$, and $2 \mathrm{CaCl}_{2}$, with the $\mathrm{pH}$ brought to 7.3. In some cases, $\mathrm{CaCl}_{2}$ was raised to $5 \mathrm{~mm}$ to improve recording stability. Standard intracellular recording techniques were used to measure end plate potentials or action potentials, while the $\mathrm{C}_{6}$ and $\mathrm{C}_{7}$ branches were stimulated with suction electrodes. Typical stimulation parameters were $1-10 \mathrm{~V}$ for $0.1 \mathrm{msec}$ at $1-3 \mathrm{~Hz}$.

Muscle contraction was prevented by raising the $\mathrm{Mg}$ concentration to $12-17 \mathrm{~mm}$ or by stretching the muscle. Intracellular recordings were made from muscle fibers of sectors II and III. Sector I was not systematically studied because the nerve crushes above this sector did not consistently denervate all the fibers in sector I.

Recording and analysis of end plate potentials. End plate potentials (EPPs) were recorded with intracellular microelectrodes and were analyzed by the method of failures (DelCastillo and Katz, 1954). This method allows for an estimate of synaptic strength without the necessity of using curare as a neuromuscular blocking agent. EPPs were recorded on a computer after digitization (Neuro Data Instruments) [for further details, see Colman et al. (1997)]. We recorded from muscle sectors II and III and studied in detail only end plates that were multiply innervated and had inputs from both $\mathrm{C}_{6}$ and $\mathrm{C}_{7}$ ventral roots. Both branches were stimulated in succession from 100-1200 times at $3 \mathrm{~Hz}$. The EPPs from both inputs were analyzed separately, and composites were spliced back together.

To determine whether an end plate was multiply innervated by axons from a single ventral root, we reduced and gradually increased the voltage. If a step in the EPP was seen before the maximal EPP size, the end plate was deemed multiply innervated by that ventral root and was no longer studied. The populations of quantal responses from two axons innervating the same end plate were compared using the KolmogorovSmirnov test for differences in the shape of the two distributions.

A graphical representation comparing quantal size was based on the techniques of Colman et al. (1997). After recording EPPs evoked in dually innervated end plates, the separate digitized EPPs from $\mathrm{C}_{6}$ and $\mathrm{C}_{7}$ were rank ordered according to amplitude. This arrangement allowed for the examination of the smallest EPPs to detect any weakening of one or another input.

Average segmental innervation (ASI) was calculated as reported previously (Laskowski and Sanes, 1987). Those recording sites with lower ASI numbers reveal a rostral bias; higher numbers represent a caudal bias. Data were analyzed by ANOVA and Student's $t$ test, and significant differences were set at the $p<0.05$ level.

Labeling of axons with 4-Di-16-Asp or DiI. Neonatal rats aged postnatal day 1 (P1)-P14 were anesthetized and decapitated before removal of the SA muscle. After the muscle along with the $\mathrm{C}_{6}$ and $\mathrm{C}_{7}$ branches forming the LTN was pinned to a Sylgard dish, a PBS solution containing $4 \%$ paraformaldehyde was added, and the preparation was placed in the cold for $24 \mathrm{hr}$. Crystals of $\mathrm{DiIC}_{22}$ (Molecular Probes, Eugene, OR) or 4-Di16-Asp (DiA; Molecular Probes) were wrapped in a coating of rubber cement and formed into "dye balls," and the proximal cut ends of the $\mathrm{C}_{6}$ or $\mathrm{C}_{7}$ nerve branches were inserted into one or the other ball (BaliceGordon et al., 1993). Dishes containing the muscles were then immersed in $0.1 \mathrm{M} \mathrm{PO}_{4}$ buffer and incubated for 1-6 months. Labeled nerves were viewed using epifluorescence excitation (for DiI, N2 narrow-band green filters; excitation, $530-560 \mathrm{~nm}$; long-pass filter, $580 \mathrm{~nm}$; for DiA, wideband blue filters; excitation, 420-490 nm; long-pass filter, $515 \mathrm{~nm}$ ). DiA-labeled axons could be clearly distinguished from DiI-axons. Junctions were imaged on a confocal microscope (Noran) using a $40 \times$ oil-immersion 1.3 numerical aperture objective.

\section{RESULTS}

\section{Normal junctions in the neonatal SA muscle}

We have published results previously of physiological recordings from neonatal SA muscle end plates (Laskowski and High, 1989). In some muscle sectors, we had found that more than one-half of 

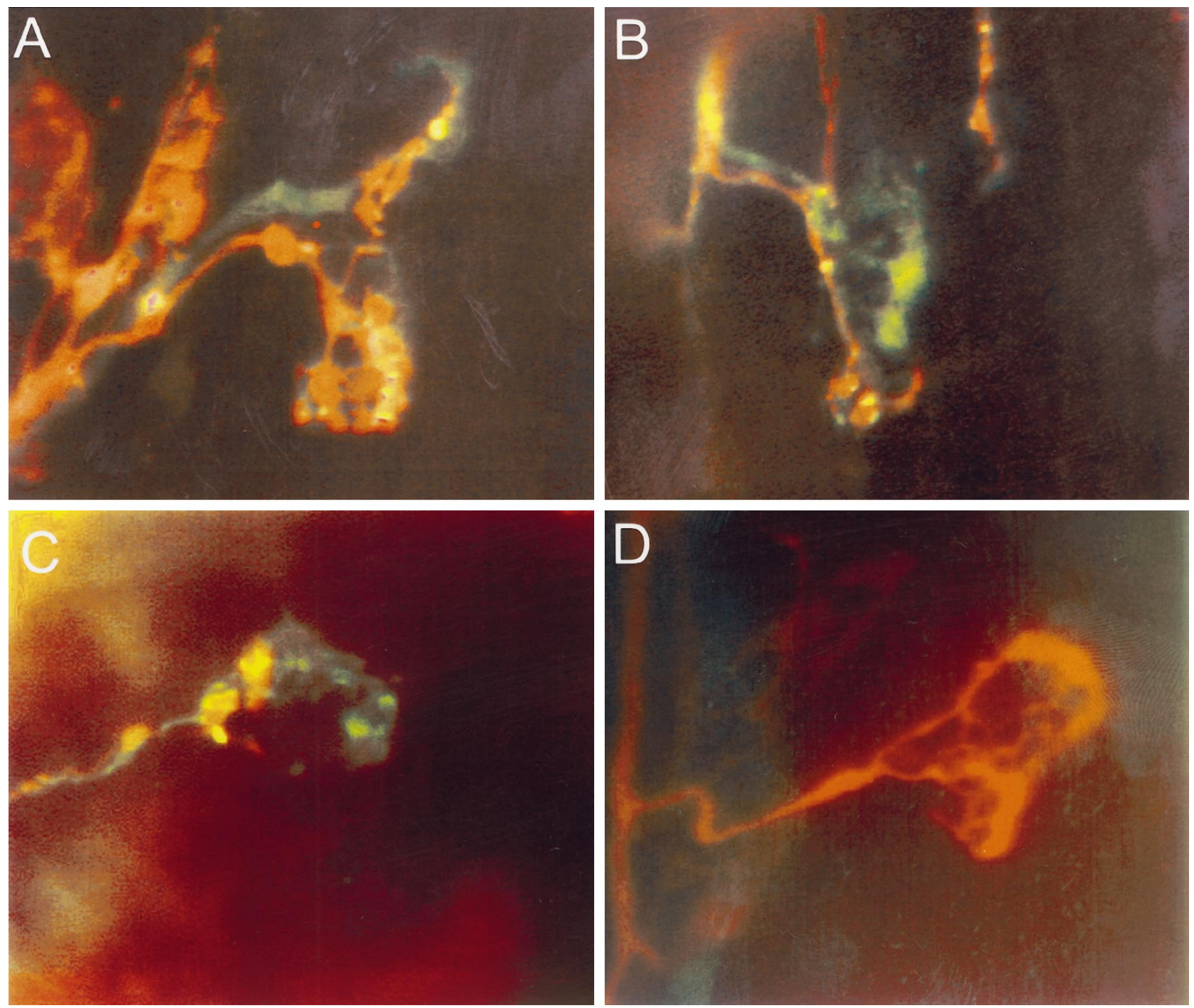

Figure 2. Fluorescently labeled $\mathrm{C}_{6}$ and $\mathrm{C}_{7}$ nerve terminals in a $\mathrm{P} 1$ serratus anterior muscle. $A, B$, Multiply innervated end plates receiving an input from both $\mathrm{C}_{6}$ (red, DiI) and $\mathrm{C}_{7}$ (green, DiA) branches. $C$, A dually innervated end plate near the end of the process of synapse elimination showing that the remaining $\mathrm{C}_{6}($ red $)$ input occupies a small area and has a thin axon. $D$, An image of a nerve terminal to an end plate singly innervated by an axon from $\mathrm{C}_{6}$.

the end plates were innervated by both the $\mathrm{C}_{6}$ and $\mathrm{C}_{7}$ branch of the LTN. Figure 2 shows the arrangement of inputs at multiply and singly innervated neuromuscular junctions. End plates with dual innervation from $\mathrm{C}_{6}$ and $\mathrm{C}_{7}$ show intermingling of terminals from both branches in the same end plate (Fig. $2 A, B$ ). This dual innervation is seen especially in caudal sectors of the muscle in which previous physiological results indicate greater contribution from the $\mathrm{C}_{7}$ branch (Laskowski and High, 1989). In some cases of multiply innervated junctions, one input occupied a proportionately smaller area and had a thin preterminal axon (Fig. 2C). Similar structural differences between inputs at multiply innervated junctions have been associated with synapse elimination in other muscles (Balice-Gordon et al., 1993). Many end plates encountered in these muscles were, however, singly innervated and usually by $\mathrm{C}_{6}$ (Fig. 2D). Thus, during early postnatal life at the time the topography is being sharpened, axons from different spinal levels temporarily converged at the same neuromuscular junction sites.

\section{Progression of reinnervation}

Ordinarily, in 1-week-old SA muscles, the ASI of sector II is 1.10 (Laskowski and High, 1989), implying that normally only $10 \%$ of

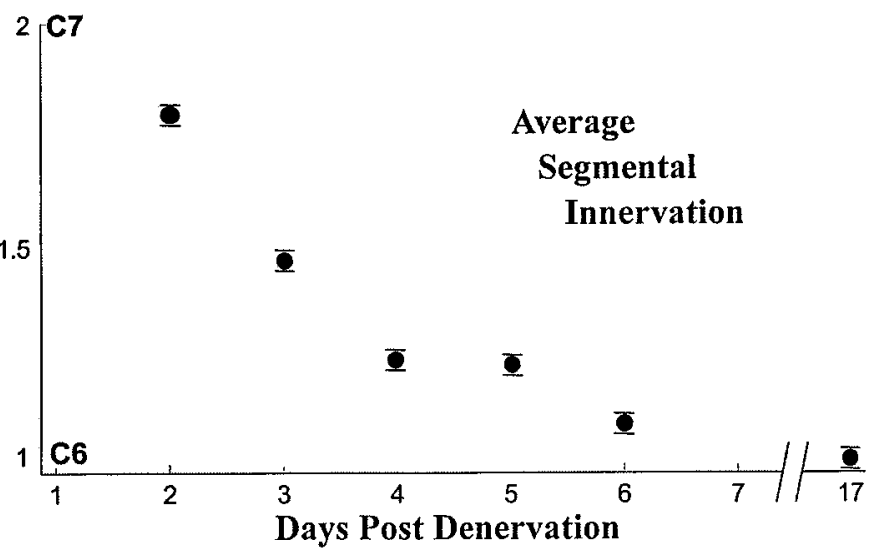

Figure 3. The ASI of sector II of the serratus anterior muscle as a function of days after denervation. The method of calculating ASI is described in the text. A high ASI indicates greater contribution by $\mathrm{C}_{7}$ to the muscle. Days after denervation represent days after the second surgical procedure. Each data point represents the mean \pm SE calculated from 20 end plates in each of 3-12 muscles. 


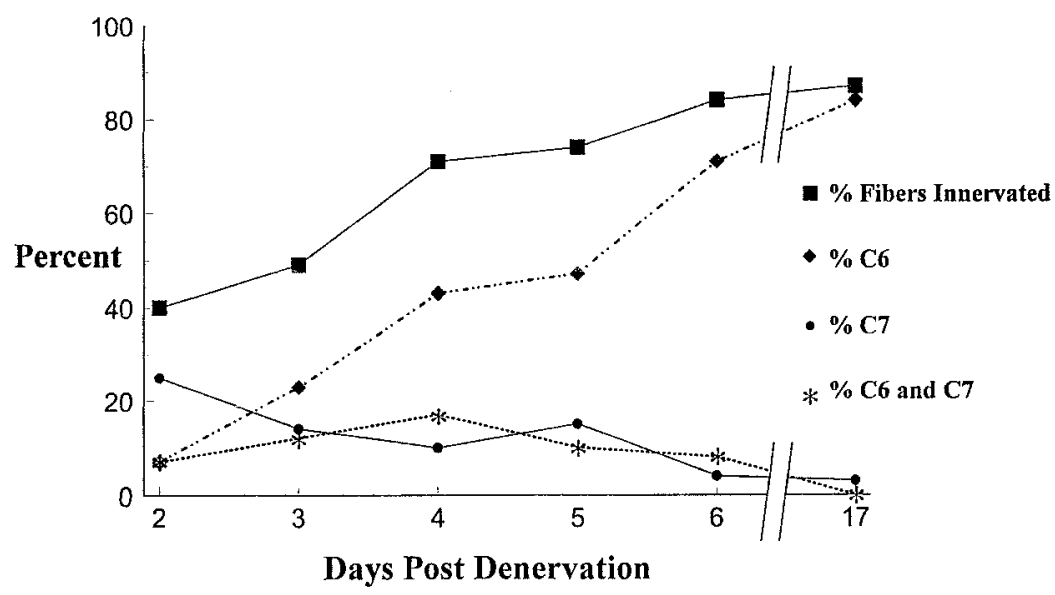

Figure 4. The contribution of motor neuron input from each nerve branch to muscle end plates expressed as a percent of all fibers sampled. Days after denervation are calculated from the day after the second surgical procedure. To obtain the estimate of the percent of fibers innervated (filled squares), we noted and recorded the result of every cell penetration with a microelectrode as either $\mathrm{C}_{6}$ only ( filled diamonds), $\mathrm{C}_{7}$ only (filled circles), both $\mathrm{C}_{6}$ and $\mathrm{C}_{7}$ (asterisks), or not innervated. All data were averaged from 20 fibers sampled in each of 3-12 muscles.

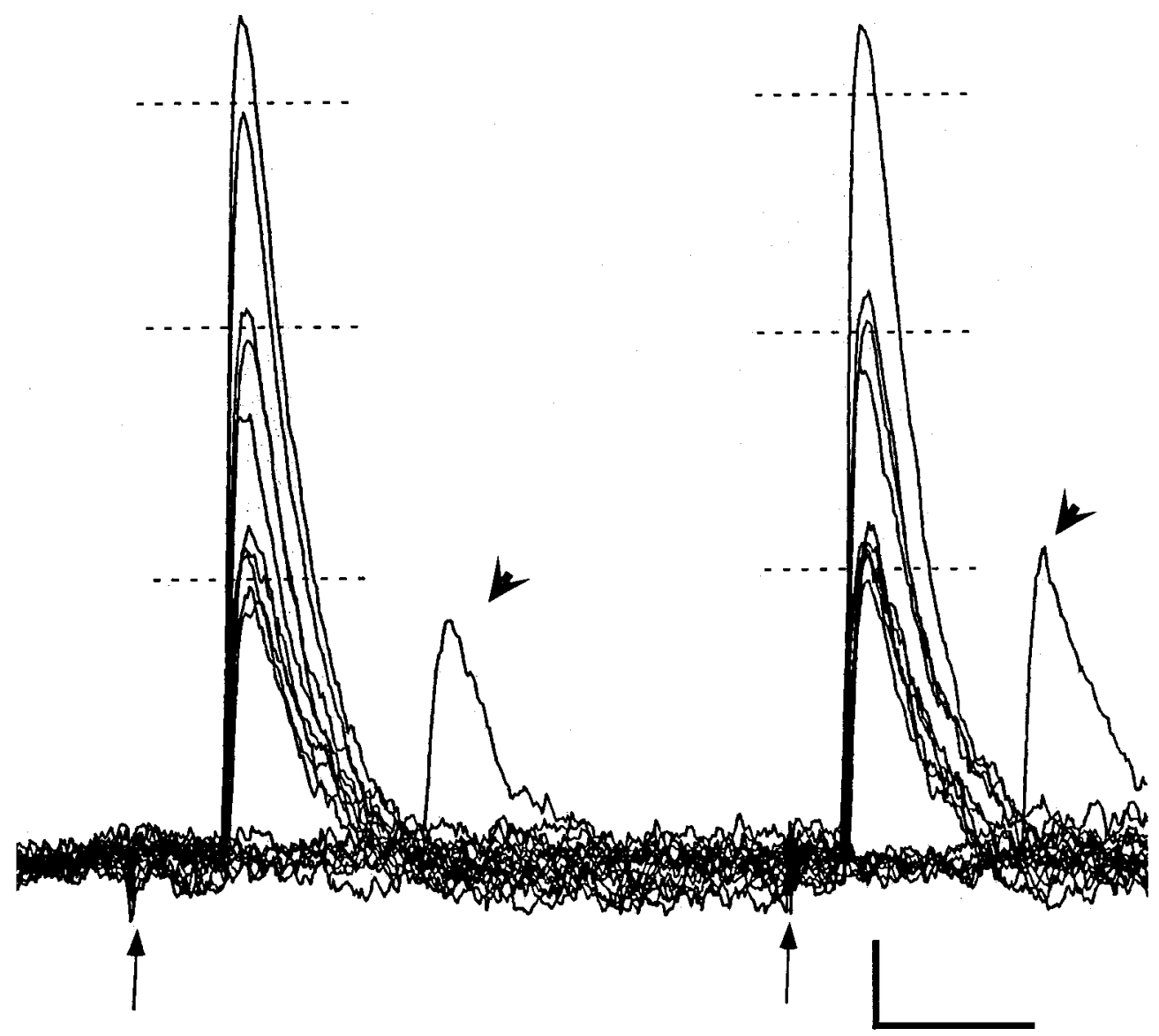

Figure 5. Sample traces of digitized EPPs recorded from a dually innervated end plate in sector II, $4 \mathrm{~d}$ after denervation (16 traces superimposed). Pairs of stimuli were applied in alternation to the $\mathrm{C}_{6}$ and $\mathrm{C}_{7}$ branch of the LTN at $3 \mathrm{~Hz}$ (arrows). Left traces resulted from the stimulation of $\mathrm{C}_{6}$; right traces resulted from the stimulation of $\mathrm{C}_{7}$. Spontaneous MEPPs (arrowheads) illustrate the amplitude of a single quantum. Note the stepwise multiquantal EPPs (dotted lines) as well as some failed responses, a typical result of low-quantum EPPs in high magnesium-blocked preparations. Both inputs have similar quantal content. Calibration: $0.5 \mathrm{mV}, 2$ msec. the input to this sector is from $\mathrm{C}_{7}$ (see Materials and Methods). Figure 3 shows the progress of reinnervation of a rostral sector (II) of SA muscles in which caudal sectors were removed and axons from the $\mathrm{C}_{7}$ branch were returned before those from $\mathrm{C}_{6}$ (see Materials and Methods). Two days after the second denervation procedure, when the earliest reinnervating inputs could be detected, the segmental innervation was shifted caudally (ASI = 1.8). The dominance by $\mathrm{C}_{7}$ gradually diminished over the next $4 \mathrm{~d}$, so that by day 6 after denervation, the ASI was 1.11, indicating that nearly all muscle fibers were exclusively innervated by $\mathrm{C}_{6}$. After $17 \mathrm{~d}$, the input was skewed even further in favor of $\mathrm{C}_{6}(\mathrm{ASI}=1.03)$. Similar results were observed in sector III (data not shown).
Because relatively few fibers were innervated at the earliest times when $\mathrm{C}_{7}$ dominated, it is possible that the shift in dominance was accounted for by the return of $\mathrm{C}_{6}$ to vacated end plates as opposed to a displacement or suppression of $\mathrm{C}_{7}$ inputs. For this reason, it was important to analyze the data as a function of all fibers sampled, whether innervated or not (Fig. 4). Two days after denervation, synaptic potentials could be evoked in only $40 \%$ of the fibers sampled. This percentage gradually increased so that synaptic potentials could be recorded from $84 \%$ of the fibers at $6 \mathrm{~d}$ and $87 \%$ at $17 \mathrm{~d}$. Three days after denervation, $25 \%$ of the total population of end plates sampled were innervated exclusively by $\mathrm{C}_{7}, 7 \%$ were innervated by $\mathrm{C}_{6}$, and the remaining $7 \%$ were innervated by both $\mathrm{C}_{6}$ and $\mathrm{C}_{7}$. Over the next $4 \mathrm{~d}$, innervation 


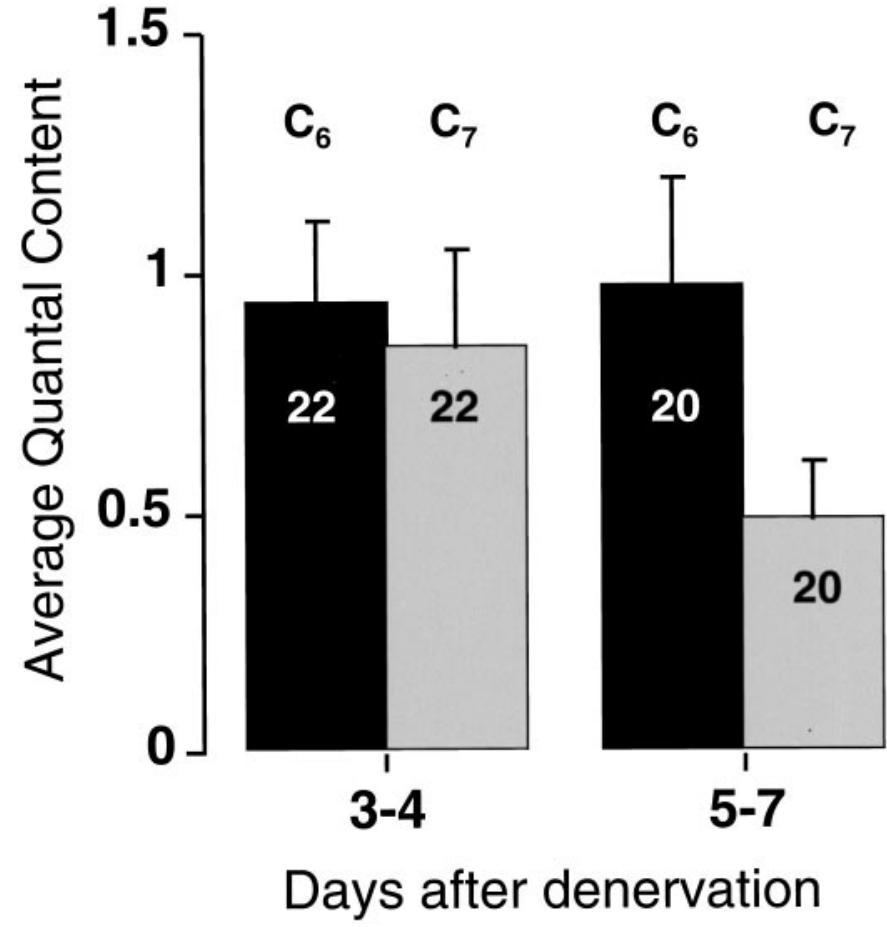

Figure 6. Measurements of the average quantal content in dually innervated end plates show that there is no difference in the strength of the synaptic input by the two branches of the LTN at 3-4 d after denervation. At 5-7 d, however, the axons from $\mathrm{C}_{6}$ are more than twice as powerful as those from $\mathrm{C}_{7}$. The data at 3-4 d were obtained from a total of 22 cells in four muscles; that at 5-7 d were from a total of 20 cells in three muscles. Data represent mean \pm SEM. Significant differences $(p<0.05)$ were seen between the quantal content of $\mathrm{C}_{6}$ and $\mathrm{C}_{7}$ at 5-7 d.

by $\mathrm{C}_{6}$ gradually increased, whereas that by $\mathrm{C}_{7}$ decreased. By $17 \mathrm{~d}$, of the 37 fibers sampled in three muscles, only one end plate $(3 \%)$ received input from $\mathrm{C}_{7}$. Thus, the contribution of $\mathrm{C}_{7}$ to sector II declined in an absolute sense over several weeks after $\mathrm{C}_{6}$ axons returned to the muscle.

One way in which the return of $\mathrm{C}_{6}$ axons could have promoted the loss of $\mathrm{C}_{7}$ input would be if the two sets of axons competed for the same neuromuscular junctions. Indeed, anatomical studies (see Fig. 2) showed that during normal development, both segments occasionally supplied innervation to the same neuromuscular junction. Consistent with this, we found that after reinnervation, a proportion of muscle fibers was functionally innervated by axons from both $\mathrm{C}_{6}$ and $\mathrm{C}_{7}$. End plates in sector II received a progressive rise and then fall of dual segmental innervation, reaching a peak of $17 \%$ of all fibers sampled by day 4 . By day 17 , we found no end plates innervated by both $C_{6}$ and $C_{7}$. Similar results were observed in sector III.

\section{Reinnervation by axons from only the $\mathbf{C}_{\mathbf{7}}$ branch}

The temporal coincidence of $\mathrm{C}_{6}$ return and $\mathrm{C}_{7}$ loss as well as the transient presence of junctions innervated by both branches suggests that the loss of $\mathrm{C}_{7}$ innervation was induced by the return of $\mathrm{C}_{6}$. To test this hypothesis, we studied the behavior of $\mathrm{C}_{7}$ axons in the complete absence of $\mathrm{C}_{6}$ input. This was accomplished by using a second method of denervation in which the branch from $\mathrm{C}_{6}$ was cut and removed to prevent reinnervation (the caudal sectors were also removed as before). Two weeks later, end plates in sectors II and III were sampled. In three muscles studied (93 cells sampled), $62 \%$ of the end plates were reinnervated by $\mathrm{C}_{7}$; none were reinnervated by $\mathrm{C}_{6}$. Thus, $\mathrm{C}_{7}$ axons are capable of sustained innervation of rostral muscle sectors in the absence of $\mathrm{C}_{6}$ axons, whereas $\mathrm{C}_{7}$ input is almost entirely eliminated in the presence of $\mathrm{C}_{6}$ axons.

\section{Removal of rostral sectors}

We next asked whether some mechanism intrinsic to $\mathrm{C}_{6}$ neurons simply gave them an advantage regardless of whether the end plate was located in rostral or caudal muscle sectors. When rostral sectors I-III were removed, the LTN navigated across a narrow bridge to reach the caudal sectors. Innervation by these regenerating axons could be detected by day 4. Six to ten days after denervation of caudal sectors, the ASI index in sectors IV-VI was $1.44 \pm 0.08$, meaning that $44 \%$ of the input came from $\mathrm{C}_{7}$ axons. This is not significantly different from the $C_{7}$ input to caudal sectors when the LTN nerve is simply crushed and all sectors are intact [1.39 \pm 0.06; recalculated from DeSantis et al. (1992)]. Thus, the dominance of $\mathrm{C}_{6}$ in rostral sectors is not based on any intrinsic advantage of $\mathrm{C}_{6}$ over $\mathrm{C}_{7}$.

\section{Quantal analysis of end plate potentials}

To determine whether synaptic competition at the level of individual end plates could account for the removal of positionally inappropriate inputs, we evaluated the quantal contents and synaptic efficacies at end plates reinnervated by one $\mathrm{C}_{6}$ and one $\mathrm{C}_{7}$ axon. Figure 5 illustrates a recording from an end plate in an SA muscle (sector II) $4 \mathrm{~d}$ after denervation. Stimulation of either $\mathrm{C}_{6}$ or $\mathrm{C}_{7}$ released $0-3$ quanta per impulse at this concentration of $\mathrm{Mg}^{2+}(\sim 17 \mathrm{~mm})$. The average quantal content calculated in all the dually innervated end plates studied 3-4 d after denervation revealed no systematic difference between the strength of $\mathrm{C}_{6}$ and $\mathrm{C}_{7}$ axons (Fig. 6). Indeed, when we looked at the strengths of inputs to individual dually innervated end plates, we found that at $4 \mathrm{~d}$, the majority of such muscle fibers (12 of 19) were more strongly innervated by $\mathrm{C}_{7}$ than by $\mathrm{C}_{6}$. Thus, at early times there certainly seems to be no systematic advantage of $C_{6}$ over $C_{7}$ in synaptic strength. However, 5 to $7 \mathrm{~d}$ after denervation, the quantal content of $\mathrm{C}_{6}$ was on average twice that of $\mathrm{C}_{7}$ at multiply innervated end plates in sector II, and at day 7 , none of the junctions ( 0 of 7 ) were dominated by $\mathrm{C}_{7}$. It should be noted that we observed a low incidence of dual innervation that met our stringent requirement that there be one and only one axon from each branch innervating the end plate, especially at the later time point. The low incidence of multiple innervation at later times presumably means that, once the quantal content is skewed in favor of $\mathrm{C}_{6}$, the complete removal of $\mathrm{C}_{7}$ occurs rapidly. A similar skewing and acceleration of the rate of competition occurs during normal development (Colman et al., 1997).

Because previous work had indicated that the efficacy of individual quanta was weakened by synaptic competition (Colman et al., 1997), we next looked at quantal size in dually innervated end plates. Stimulation of $\mathrm{C}_{6}$ and $\mathrm{C}_{7}$ to elicit evoked release was strictly alternated to obviate any time-dependent changes between the synaptic responses of the terminals from the two branches. Figure 7 is a graphical representation of quantal size using the method of failures for one end plate from sector II, $7 \mathrm{~d}$ after denervation. The two columns of Ranked EPPs show the rank order of EPP amplitudes elicited by stimulation of $\mathrm{C}_{6}$ (left) and $\mathrm{C}_{7}$ (right). The smallest synaptic responses from each axon represent the postsynaptic depolarization from single quanta (quantal efficacy). There were fewer failures in response to stimulation of $\mathrm{C}_{6}$ compared with $\mathrm{C}_{7}$, indicating larger quantal content 


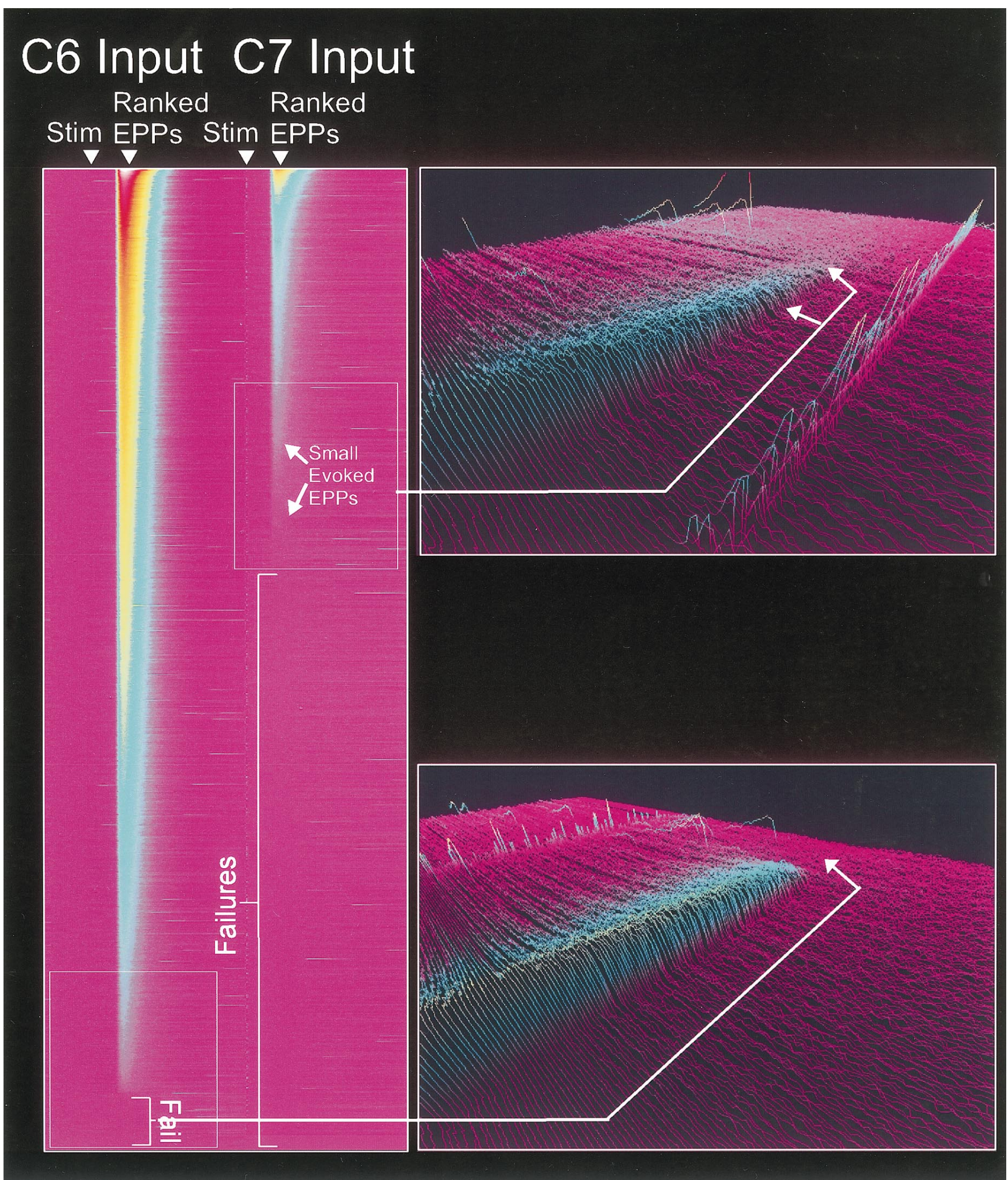

Figure 7. Evidence of small EPPs at a dually innervated end plate $7 \mathrm{~d}$ after denervation. The 500 traces show the response of stimulating $\mathrm{C}_{6}$ and $\mathrm{C}_{7}$ branches of the LTN (Stim) while recording intracellularly from a muscle fiber in sector II in the presence of high $\mathrm{Mg}^{2+}$. The responses of each nerve branch were replotted in order of decreasing amplitude [Ranked EPPs; for further details, see Materials and Methods and Colman et al. (1997)]. Red (false coloring by amplitude) represents high amplitude, and purple represents resting potential. Note that below the smallest evoked synaptic responses (blue) are "failures" in which no EPP was observed. At this end plate, the $\mathrm{C}_{7}$ terminals had on average smaller EPPs and many more failures and therefore lower quantal content. In addition, the boxed regions of the "tails" of the smallest (and therefore unitary) quantal responses showed significantly lower amplitude for the $\mathrm{C}_{7}$ input. The amplitude of the smallest evoked responses from each nerve branch was visualized in height on the right. Responses from the $\mathrm{C}_{6}$ axon (lower right) show an abrupt shoulder between the smallest EPP and the failures. On the other hand, the responses after stimulation of the $\mathrm{C}_{7}$ input (upper right) show small EPPs whose amplitudes merge with the baseline resting noise. Such very small quantal responses are indicative of retracting terminals at junctions undergoing synaptic competition and elimination. 


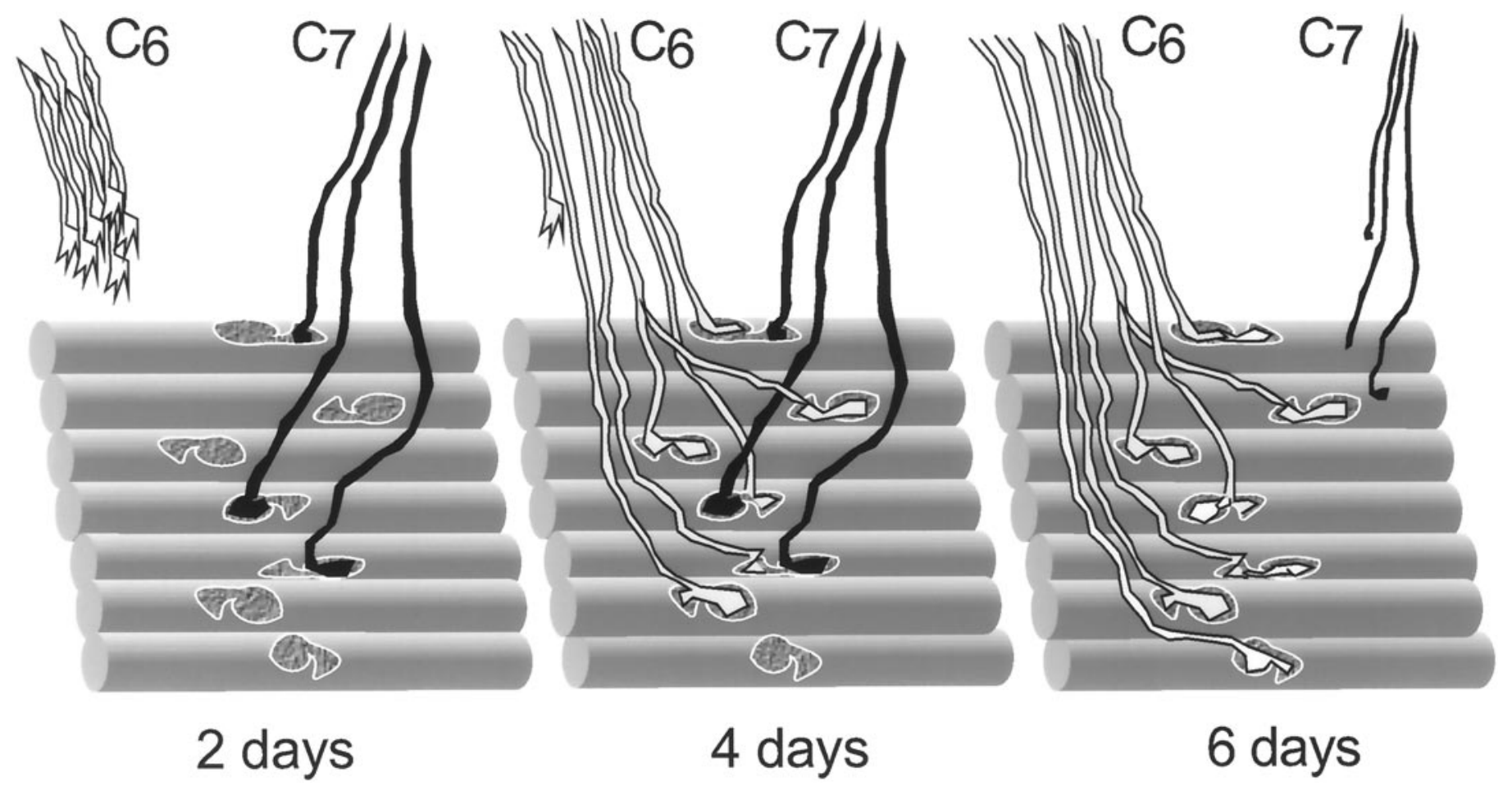

Figure 8. A diagram of delayed reinnervation of a rostral sector of the SA muscle showing the progression from innervation by ventral root $\mathrm{C}_{7}$, to input from $\mathrm{C}_{6}$ and $\mathrm{C}_{7}$ levels, and finally to almost exclusive input by $\mathrm{C}_{6}$. At day 2 after denervation, $\mathrm{C}_{7}$ terminals have unopposed access to vacated end plates in muscle sector II. However, because of the smaller number of $\mathrm{C}_{7}$ terminals, they occupy only one-half of the vacated end plates. When $\mathrm{C}_{6}$ terminals re-enter the end plate zone, they reinnervate unoccupied end plates and coinnervate end plates that were occupied previously by $\mathrm{C}_{7}$ terminals. Eventually $\mathrm{C}_{7}$ terminals in these dually innervated end plates are displaced or suppressed by $\mathrm{C}_{6}$ terminals, and the normal pattern of $\mathrm{C}_{6}$ input to this muscle sector is re-established.

from $\mathrm{C}_{6}$. In addition, there were no small, evoked EPPs from $\mathrm{C}_{6}$. The transition from smallest evoked EPP to failure was abrupt. The lower left boxed region illustrates this distinct transition more clearly. Conversely, in the upper boxed region, the transition from smallest evoked EPP to failures is less distinct for the $\mathrm{C}_{7}$ input. The upper right panel shows that the smallest $\mathrm{C}_{7}$ EPPs merge with the baseline noise without a distinct transition from evoked potential to failure, suggesting a population of quantal responses from $\mathrm{C}_{7}$ with significantly lower quantal efficacy than those from $\mathrm{C}_{6}$. Previous work supported the idea that small quantal responses were caused by a change in the density of postsynaptic ACh receptors at sites undergoing imminent synapse removal (Colman et al., 1997).

We recorded in high $\mathrm{Mg}^{2+}$ between 2 and $7 \mathrm{~d}$ after denervation from 60 muscle fibers that met the stringent requirement that they were multiply innervated by an axon from $\mathrm{C}_{6}$ and by an axon from $\mathrm{C}_{7}$. In each of these cells, we analyzed the amplitudes of evoked potentials as shown in Figure 7. In $18(30 \%)$ of these fibers, we observed small evoked potentials from one or more inputs. In 15 out of 18 of these cases $(83 \%)$, the small evoked potentials were associated with the input from $\mathrm{C}_{7}$. The presence of small evoked potentials suggests that not only changes in quantal content but also changes in quantal size may be instrumental in the emergence of topographic specificity during reinnervation.

\section{DISCUSSION}

\section{Evidence of competition}

These observations extend previous results from our laboratory showing selective reinnervation of the SA muscle (Laskowski and Sanes, 1988; Reis and Laskowski, 1993). By delaying reinnerva- tion by a rostral pool of regenerating motor neurons to their appropriate target and removing the normal target of a caudal pool of motor neurons, we were able to force an interaction between a foreign (that is, caudal) set of motor neurons and the appropriate rostral neurons when they regenerated to the same muscle. The result of this interaction was clear evidence of competition between axons from different spinal levels for innervation of the same muscle (Fig. 8). In particular, we observed that the foreign $\left(\mathrm{C}_{7}\right)$ terminals formed functional synaptic contacts with a muscle sector that was normally nearly exclusively innervated by rostral motor neurons. Furthermore, these connections were stably maintained for weeks if the rostral pool of motor neurons was prevented from returning to the muscle. On the other hand, when the rostral pool was allowed to reinnervate the muscle, we found that the caudal pool was essentially completely displaced. Thus, the fate of the caudal innervation was directly related to whether or not the rostral pool was present. This competition was not based on any intrinsic deficit in caudal neuron competitive vigor because when rostral sectors were removed, caudal motor neurons maintained their innervation of caudal sectors in the face of innervation by rostral neurons.

Two lines of evidence suggest that the locus of competition is at individual end plates. First, in P1 muscles we found evidence of fibers that received input from both rostral and caudal pools of motor neurons at the same end plate (Fig. 2). Second, intracellular recording indicated that individual muscle fibers received functional innervation from both pools. The proximity of the competitors within an end plate suggests that some form of synaptic competition might underlie the disappearance of caudal motor neurons in rostral muscle sectors. This idea was supported 
by an analysis of the synaptic efficacy of axons from different spinal segments that converged at the same neuromuscular junction.

\section{Analysis of dually innervated end plates}

The innervation of end plates that became dually innervated by rostral and caudal axons progressed toward a predictable outcome. Such end plates were only transiently innervated by inputs from both spinal levels, so that by 2 weeks after denervation, such dual innervation had completely disappeared (from a peak of $17 \%$ of muscle fibers at 4 d). As multiple innervation was disappearing, the strength of synaptic input to individual neuromuscular junctions underwent a shift. Whereas many end plates received stronger innervation from caudal motor neurons at 3-4 d, by 5-7 d the situation was strongly reversed, and rostral motor neurons dominated every dually innervated junction studied.

While recording quantal synaptic responses from dually innervated end plates, we observed a subpopulation of small amplitude-evoked potentials. Previously, such small quantal events had been shown to be associated with the process of synaptic competition at multiply innervated neuromuscular junctions during development (Colman et al., 1997). In these dually innervated junctions, we found the axon destined to be eliminated $\left(\mathrm{C}_{7}\right)$ was more likely to evoke small synaptic potentials. We also observed occasionally that either both inputs or only the dominant input evoked small EPPs. This is reminiscent of normal development in which it appears that both competing axons yield some territory during synaptic competition (Colman et al., 1997; Gan and Lichtman, 1997). The presence of such weak quanta in this situation may mean that the competition between motor neurons from different spinal levels is occurring via the process of synapse elimination as it removes all but one input to a muscle. If synapse elimination is a means by which segmental identity is mapped onto specific muscle sectors in the serratus anterior, positional bias can influence synaptic competition in some muscles but apparently not all (Thompson, 1983). Rather than suggesting the notion that synaptic competition is strictly a function of differences in neuronal activity patterns, this work suggests that in some circumstances, at least, the competition is also biased by differences in the rostrocaudal position of the motor neurons. How such positional identity could express itself in the synapse elimination process is not at present known.

\section{REFERENCES}

Balice-Gordon RJ, Chua CK, Nelson CC, Lichtman JW (1993) Gradual loss of synaptic cartels precedes axon withdrawal at developing neuromuscular junctions. Neuron 11:801-815.

Bennett MR, Ho S (1988) The formation of topographical maps in developing rat gastrocnemius muscle during synapse elimination. J Physiol (Lond) 396:471-496.

Bennett MR, Lavidis NA (1984a) Segmental motor projections to rat muscles during the loss of polyneuronal innervation. Dev Brain Res 13:1-7.

Bennett MR, Lavidis NA (1984b) Development of the topographical projection of motor neurons to a rat muscle accompanies loss of polyneuronal innervation. J Neurosci 4:2204-2212.

Bodian D (1936) A new method for staining nerve fibers and nerve endings in mounted paraffin sections. Anat Rec 65:89-97.

Brown MC, Booth CM (1983a) Segregation of motor nerves on a segmental basis during synapse elimination in neonatal muscles. Brain Res 273:188-190.

Brown MC, Booth CM (1983b) Postnatal development of the adult pattern of motor axon distribution in rat muscle. Nature 304:741-742.
Brown MC, Hardman VJ (1987) A reassessment of the accuracy of reinnervation by motoneurons following crushing or freezing of the sciatic or lumbar spinal nerves of rats. Brain 110:695-705.

Brown MC, Hopkins WG (1981) Role of degenerating axon pathways in regeneration of mouse soleus motor axons. J Physiol (Lond) 318:365-373.

Colman H, Nakebura J, Lichtman JW (1997) Alterations in synaptic strength preceding axon withdrawal. Science 275:356-361.

DelCastillo J, Katz B (1954) Quantal components of the endplate potential. J Physiol (Lond) 124:560-573.

DeSantis M, Berger PK, Laskowski MB, Norton AS (1992) Regeneration by skeletomotor axons in neonatal rats is topographically selective at an early stage of reinnervation. Exp Neurol 116:229-239.

Donselaar Y, Kernell D, Eerbeek O, Verhey BA (1985) Somatotopic relations between spinal motoneurons and muscle fibers of the cat's musculus peroneus longus. Brain Res 335:81-88.

Gan W-b, Lichtman JW (1997) Nerve terminals at multiply innervated neuromuscular junctions segregate during developmental synapse elimination. Soc Neurosci Abstr 23:1409.

Gordon DC, Richmond FJR (1990) Topography in the phrenic motoneuron nucleus demonstrated by retrograde multiple-labelling techniques. J Comp Neurol 292:424-434.

Grow WA, Kendall-Wassmuth E, Ulibarri C, Laskowski MB (1995) Differential delay of reinnervating axons alters specificity in the rat serratus anterior muscle. J Neurobiol 26:553-562.

Hardman VJ, Brown MC (1987) Accuracy of reinnervation of rat internal intercostal muscles by their own segmental nerves. J Neurosci 7:1031-1036.

Ide C, Kato S (1990) Peripheral nerve regeneration. Neurosci Res [Suppl] 13:S157-S164.

Ide C, Tohyama K, Yokota R, Nitatori T, Onodera S (1983) Schwann cell basal lamina and nerve regeneration. Brain Res 288:61-87.

Laskowski MB, High JA (1989) Expression of nerve-muscle topography during development. J Neurosci 9:175-182.

Laskowski MB, Owens JL (1994) Embryonic expression of motoneuron topography in the rat diaphragm muscle. Dev Biol 166:502-508.

Laskowski MB, Sanes JR (1987) Topographic mapping of motor pools onto skeletal muscles. J Neurosci 7:252-260.

Laskowski MB, Sanes JR (1988) Topographically selective reinnervation of adult mammalian skeletal muscles. J Neurosci 8:3094-3099.

Laskowski MB, Norton AS, Berger PK (1991) Branching patterns of the rat phrenic nerve during development and reinnervation. Exp Neurol 113:212-220.

Mutai M, Shibata H, Suzuki T (1986) Somatotopic organization of motoneurons innervating the pronators, carpal and digital flexors and forepaw muscles in the dog: a retrograde horseradish peroxidase study. Brain Res 371:90-95.

Reis FW, Laskowski MB (1993) Selective reinnervation of the rat serratus anterior muscle following denervation and partial target removal. Exp Neurol 123:303-305.

Swett JS, Eldred E, Buchwald JS (1970) Somatotopic cord-to-muscle relations in efferent innervation of cat gastrocnemius. Am J Physiol 219:762-766.

Thompson WJ (1983) Lack of segmental selectivity in elimination of synapses from soleus muscle of new-born rats. J Physiol (Lond) 335:343-352.

Weeks OI, English AW (1985) Compartmentalization of the cat lateral gastrocnemius motor nucleus. J Comp Neurol 235:255-267.

Weeks OI, English AW (1987) Cat triceps surae motor nuclei are organized topologically. Exp Neurol 96:163-177.

Welt C, Abbs JH (1990) Musculotopic organization of the facial motor nucleus in Macaca fascicularis: a morphometric and retrograde tracing study with cholera toxin B-HRP. J Comp Neurol 291:621-636.

Wigston DJ, Sanes JR (1982) Selective reinnervation of adult mammalian muscle by axons from different segmental levels. Nature 299:464-467.

Wigston DJ, Sanes JR (1985) Selective reinnervation of intercostal muscles transplanted from different segmental levels to a common site. J Neurosci 5:1208-1221. 